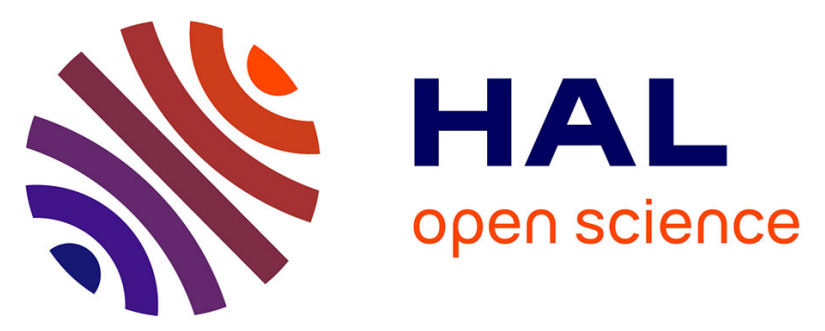

\title{
Estimating some parameters of the equatorial ionosphere electrodynamics from ionosonde data in West Africa
}

F.O. Grodji, V. Doumbia, K. Boka, Christine Amory-Mazaudier, Y. Cohen, Rolland Fleury

\section{To cite this version:}

F.O. Grodji, V. Doumbia, K. Boka, Christine Amory-Mazaudier, Y. Cohen, et al.. Estimating some parameters of the equatorial ionosphere electrodynamics from ionosonde data in West Africa. Advances in Space Research, 2016, 10.1016/j.asr.2016.09.004 . hal-01368412

\section{HAL Id: hal-01368412 \\ https://hal.sorbonne-universite.fr/hal-01368412}

Submitted on 19 Sep 2016

HAL is a multi-disciplinary open access archive for the deposit and dissemination of scientific research documents, whether they are published or not. The documents may come from teaching and research institutions in France or abroad, or from public or private research centers.
L'archive ouverte pluridisciplinaire HAL, est destinée au dépôt et à la diffusion de documents scientifiques de niveau recherche, publiés ou non, émanant des établissements d'enseignement et de recherche français ou étrangers, des laboratoires publics ou privés. 
Estimating some parameters of the equatorial ionosphere electrodynamics from ionosonde data in West Africa.

F. O. Grodji ${ }^{1}$, V. Doumbia ${ }^{1}$, K. Boka ${ }^{1}$, C. Amory-Mazaudier ${ }^{2,3}$, Y. Cohen ${ }^{4}$, R. Fleury ${ }^{5}$

1- Université Felix Houphouët Boigny, UFR-SSMT, Laboratoire de Physique de l'Atmosphère , 22 BP 582 Abidjan 13, côte d'ivoire.

2- Sorbonne Universités, UPMC Univ. Paris 06, UMR 7648, Laboratoire de Physique des Plasmas, F-75005, Paris, France

3- T/ICT4D, ICTP, International Centre for Theoretical Physics, StradaCostiera, 11 ,I 34151 Trieste Italy

4- Université Paris Diderot - Institut de Physique du Globe de Paris (IPGP), Planetary and Space Sciences, 35 rue Hélène Brion - Case 7071, Lamarck A, 75205 Paris Cedex 13, France

5- MO - Dépt. Micro-Ondes//Lab-STICC/UMR CNRS 6285 - Télécom Bretagne Technopole de Brest-Iroise, 29285 Brest, France.

Corresponding Author : Vafi Doumbia, email: vafid@yahoo.fr, phone: +22508934406 


\section{Abstract}

During the International Equatorial Electrojet Year (IEEY), an IPS-42 ionosonde located at Korhogo $\left(9.33^{\circ} \mathrm{N}, 5.42^{\circ} \mathrm{W},-1.88^{\circ}\right.$ dip-lat $)$ and a meridian chain of 10 magnetic stations were setup in West Africa $\left(5^{\circ}\right.$ West longitude). In this work, some characteristic parameters of the equatorial electrojet were estimated on the basis of the IPS-42 ionosonde data at Korhogo during the years 1993 and 1994. The study consisted of determining the zonal electric field through an estimate of the plasma vertical drift velocity. The daytime plasma vertical drift velocity was estimated from the time rates of change of the F-layer virtual height variations and a correction term that takes into account the ionization production and recombination effects. This method resulted in an improved vertical drift velocity, which was found to be comparable to the results of previous studies. The estimated vertical drift velocity was used in a semi-empirical approach which involved the IRI-2012 model for the Pedersen and Hall conductivities and the IGRF-10 model for the geomagnetic main field intensity. Thus the zonal and polarization electric fields on one hand, and the eastward Pedersen, Hall and the equatorial electrojet current densities on the other hand, were estimated. Furthermore the integrated peak current density at the EEJ center was estimated from ionosonde observations and compared with that inferred from magnetometer data. The integrated EEJ peak current densities obtained from both experiments were found to be in the same order and their seasonal variations exhibit the same trends as well.

Keywords: Equatorial Ionosphere, Equatorial electrojet, IPS-42 ionosonde, Electric fields and currents. 


\section{Introduction}

At the geomagnetic dip-equator, the orthogonally crossed eastward electric field and northward geomagnetic field combine with the differential motions between ions and electrons in the E-region of ionosphere, to produce a strong vertical polarization electric field. This electric field associates with the northward geomagnetic field to increase the east-west electrical conductivity along the geomagnetic dip-equator in a narrow latitude band of \pm 3 degrees (Cowling, 1933; Martyn, 1948; Baker and Martyn, 1953 and Sugiura and Cain, 1966). This process setup an intense eastward current, known as "equatorial electrojet" (Chapman, 1951) along the geomagnetic dip equator. In addition, occurrences of phenomena like equatorial spread F, plasma bubbles and diverse plasma density irregularities, which disturb radio waves propagation near the dip-equator, are associated with this special characteristic of the equatorial ionosphere.

Due to the EEJ current flow, the daily regular variations of the geomagnetic field horizontal component $(\mathrm{H})$ are enhanced by a ratio of 2 to 2.5 near the dip-equator (Bartels and Johnston, 1940, Fambitakoye and Mayaud, 1976, Doumouya et al., 1998). Thus most of the spatial and temporal characteristics of the EEJ (latitude, longitude and height dependence; local time, day to day and seasonal variability, as well as the dependence on solar cycle) have been evidenced from its magnetic effects. Those effects were estimated from ground-based magnetic observations (Forbush and Casaverde, 1961; Onwumechili, 1967; Fambitakoye and Mayaud, 1976; Hesse, 1982; Doumouya and al, 1998, 2003); as well as from rockets (Sampath and Sastry, 1979) and polar-orbiting satellites observations (Cain and Sweeney, 1973, Onwumechili and Agu, 1981., Jadhav et al., 2002, Doumouya and Cohen, 2004, Lühr et al., 2004, Le Mouel et al., 2006; Alken and Maus., 2007). In particular, the EEJ width, thickness, position of its center and especially its peak current density, known as the EEJ parameters, are usually inferred from its magnetic effects (Onwumechili, 1967; Fambitakoye 
and Mayaud, 1976; Doumouya et al, 1998, Rabiu et al, 2013). In addition, Anderson et al., (2002; 2004 and 2006) proposed an empirical method to determine the equatorial F-region plasma vertical drift velocity from the EEJ magnetic effects. This method consists of using an estimate of the EEJ contribution $(\Delta H)$ in the daily variations of the geomagnetic field horizontal component $(H)$. However, most parameters of the equatorial electrodynamics cannot be reliably estimated from magnetic data alone. Among these parameters, the zonal electric field $\left(\vec{E}_{y}\right)$, the vertical polarization electric field $\left(\vec{E}_{p}\right)$, the eastward Pedersen $\left(\vec{J}_{p 1}\right)$ and Hall current $\left(\vec{J}_{H 2}\right)$ densities and the net eastward EEJ current density $\left(\vec{J}_{E E J}\right)$ can be mentioned.

At the dip-equator, the zonal electric field and the northward geomagnetic field combine to produce the F-region plasma vertical drift. The zonal electric field can be approximately estimated if the F-region plasma vertical drift velocity and the geomagnetic main field intensity are known. While the geomagnetic field intensity can be easily estimated at any location through accurate models like IGRF, the F-region plasma vertical drift velocity, on the contrary, is harder to get everywhere. In fact satellite measurements provided the global view of equatorial F-region plasma drifts and associated electric field (Maynard et al., 1988; Coley and Heelis, 1989; Coley et al., 1990; Heelis and Coley, 1992). Those measurements depicted the longitudinal, seasonal and solar cycle effects (see Fejer et al., 1995 and references therein). In addition, regional climatology models of the equatorial Fregion plasma drift velocity were developed in the Peruvian, Brazilian and Indian longitude sectors (Scherliess and Fejer, 1999). Richmond et al. (1980) and Fejer (1999) reported as well on global empirical models of magnetically quiet time equatorial F-region vertical drift velocity.

Other studies of the equatorial F-region plasma vertical drifts were performed using various techniques of measurements. For example, Ionosondes and HF Doppler radars have been used to study the equatorial F-region vertical drifts (Namboothiri et al., 1989; Goel et al., 
1990; Krishna Murthy et al., 1990; Hari and Krishna Murthy, 1995, Blanc and Houngninou, 1998). The most reliable measurements of the F-region plasma vertical drift velocity near the geomagnetic dip-equator were performed by Incoherent Scatter Radar at Jicamarca (Woodman, 1970; Farley et al., 1970 and Fejer et al., 1991). However, such reliable measurements of the equatorial F-region plasma vertical drift are not available everywhere. In the African longitude sector, only ionosonde data can be used for such purpose (Iheonu and Oyekola, 2005; Oyekola and Oluwafemi, 2007). However, Woodman et al. (2006) and Bertoni et al. (2006) compared the rate of F-layer height variations $\left(\frac{d h^{\prime} F}{d t}\right)$ from digisonde data with vertical drift inferred from Jicamarca Incoherent Scatter Radar data. A fairly good agreement was found between digisonde $\left(\frac{d h^{\prime} F}{d t}\right)$ and incoherent scatter radar results during Pre-reversal Enhancement, when electric convection effects are significantly dominant over recombination and production effects (Woodman et al., 2006). Redmon et al. (2010) also found a quasi perfect linear correlation between the h'F and the vertical drift velocity during the Pre Reversal Enhancement at Jicamarca. For the rest of the time, when production and recombination are important, Woodman et al. (2006) found that digisonde $\left(\frac{d h^{\prime} F}{d t}\right)$ does not accurately represent the real F-region vertical drift. However, they assumed that digisonde derived F-region vertical drift could be improved by taking into account the production and recombination effects. Iheonu and Oyekola (2005) and Oyekola and Oluwafemi (2007) considered the production and recombination effects to estimate the daytime plasma vertical drift velocity.

In this work, a comparative study based on the IPS-42 ionosonde data and the magnetic data is carried out. The plasma vertical drift velocity $\left(V_{d}\right)$ is estimated on the basis of the IPS-42 ionosonde data recorded at Korhogo (Vila et al., 1998) during the IEEY campaign. Based on the subsequent plasma vertical drift velocity, an attempt of estimating the 
zonal electric field $\left(\vec{E}_{y}\right)$, the vertical polarization electric field $\left(\vec{E}_{p}\right)$, the eastward Pedersen $\left(\vec{J}_{p 1}\right)$ and Hall current $\left(\vec{J}_{H 2}\right)$ densities and the net eastward current density $\left(\vec{J}_{E E J}\right)$ will be made. In addition the integrated peak current density $\left(I_{0}\right)$ at the EEJ center will be estimated by integrating the net eastward EEJ current density $\left(\vec{J}_{E E J}\right)$ in height. The results of the integrated peak current density inferred from ionosonde data $\left(I_{0 i}\right)$ will be compared with that obtained from ground-based magnetic data $\left(I_{0 m}\right)$ in West Africa.

\section{Basic equations}

Figure 1 schematically summarizes in 3 steps the processes that lead to the equatorial electrojet current flow (Martyn, 1948 and Baker and Martyn, 1953).

\section{Step 1:}

In the dynamo region of the ionosphere near the dip-equator, the horizontal northward geomagnetic field $\vec{B}$ and zonal electric field $\overrightarrow{E_{y}}$, produce an eastward Pedersen current $\overrightarrow{J_{p 1}}$ (Eq. 1), and a vertical downward Hall current $\overrightarrow{J_{H 1}}$ (Eq. 2) associated with electrons upward vertical $\vec{E} \times \vec{B}$ drift.

$\overrightarrow{J_{p 1}}=\sigma_{p} \overrightarrow{E_{y}}$

$\overrightarrow{J_{H 1}}=-\sigma_{H}\left(\frac{\overrightarrow{E_{y}} \times \vec{B}}{B}\right)$

$\sigma_{p}$ and $\sigma_{H}$ are respectively Pedersen and Hall conductivities.

\section{Step 2:}

On one hand, as ions $\vec{E} \times \vec{B}$ drift is impeded in the E-region due to collisions with neutral particles while electrons are relatively free to move, the resulting charge separation gives rise to an upward vertical polarization electric field $\left(\overrightarrow{E_{p}}\right)$. On the other hand, $\overrightarrow{E_{p}}$ gives rise to an upward vertical Pedersen current $\overrightarrow{J_{p 2}}$ (Eq. 3):

$\overrightarrow{J_{p 2}}=\sigma_{p} \overrightarrow{E_{p}}$

Eq. (3) 
And the $\overrightarrow{E_{p}} \times \vec{B}$ westward electron drift gives rise to an intense eastward Hall current $\overrightarrow{J_{H 2}}$ (Eq. 4):

$\overrightarrow{J_{H 2}}=-\sigma_{H}\left(\frac{\overrightarrow{E_{p}} \times \vec{B}}{B}\right)$

Step 3:

When the polarization process is complete, the upward vertical Pedersen current $\overrightarrow{J_{p 2}}$ counterbalances the downward Hall current $\overrightarrow{J_{H 1}}$ (Figure 1), then the net vertical current becomes nil (Eq.5 and Eq.6):

$\overrightarrow{J_{z}}=\overrightarrow{J_{H 1}}+\overrightarrow{J_{p 2}}=0$

Eq. (5)

$\overrightarrow{J_{z}}=\sigma_{p} \overrightarrow{E_{p}}-\sigma_{H}\left(\frac{\overrightarrow{E_{y}} \times \vec{B}}{B}\right)=0$

Eq. (6)

The eastward Hall current $\overrightarrow{J_{H 2}}$ superimposes the primary eastward Pedersen current $\overrightarrow{J_{p 1}}$. Thus the total eastward current density is:

$\overrightarrow{J_{E E J}}=\overrightarrow{J_{p 1}}+\overrightarrow{J_{H 2}}=\sigma_{p} \overrightarrow{E_{y}}-\sigma_{H}\left(\frac{\overrightarrow{E_{p}} \times \vec{B}}{B}\right)$

From Eq. (6) the vertical polarization electric field can be expressed by Eq. (8):

$\overrightarrow{E_{p}}=\frac{\sigma_{H}}{\sigma_{p}}\left(\frac{\overrightarrow{E_{y}} \times \vec{B}}{B}\right)$

Replacing $\overrightarrow{E_{p}}$ in Eq. (7), the equatorial electrojet net current density can be expressed as:

$\overrightarrow{J_{E E J}}=\left(\sigma_{p}+\frac{\sigma_{H}^{2}}{\sigma_{p}}\right) \overrightarrow{E_{y}}$

Where $\sigma_{C}=\sigma_{p}+\frac{\sigma_{H}^{2}}{\sigma_{p}}$ is the net eastward conductivity known as "Cowling conductivity".

The polarization electric field $\overrightarrow{E_{p}}$ and the EEJ current density $\overrightarrow{J_{E E J}}$ can be estimated respectively through Eq. (8) and Eq. (9), if the zonal electric field $\overrightarrow{E_{y}}$, the geomagnetic field intensity $B$, the Pedersen conductivity $\sigma_{p}$ and the Hall conductivity $\sigma_{H}$ are known. In this work, we used the Pedersen and Hall conductivities integrated along the geomagnetic field 
lines. The integrated Pedersen $\left(\sum_{P}\right)$ and Hall $\left(\sum_{H}\right)$ conductivities are estimated through the local conductivities that are determined from the IRI-2012 model. The geomagnetic field intensity $(B)$ is estimated from the IGRF-10 model. The zonal electric field $\left(\overrightarrow{E_{y}}\right)$ is determined through Eq. (10) from the plasma vertical drift velocity $\left(\vec{V}_{d}\right)$ that will be estimated from the IPS-42 ionosonde data at Korhogo.

$\vec{V}_{d}=\frac{\overrightarrow{E_{y}} \times \vec{B}}{B^{2}}$

\section{Datasets and data processing}

During the International Equatorial Electrojet Year (IEEY), many different instruments were deployed in West Africa from 1992 to 1995 (Amory- Mazaudier et al., 1993). The campaign involved a network of three ionosondes, a Fabry-Perrot interferometer (Vila et al., 1998) and an HF radar (Blanc and Houngninou, 1998). A meridian chain of ten magnetic stations was deployed across the geomagnetic dip-equator, from $-6.30^{\circ}$ to $+6.76^{\circ}$ dip-latitudes (Doumouya et al., 1998 and Vassal et al.,1998). Figure 2 shows the ionosonde location and the magnetometer network. The geographic coordinates of the stations are given in Table 1. At that occasion, variations of the geomagnetic field and various parameters of low-latitude ionosphere have been monitored in view of deepening our knowledge on equatorial and low latitude electromagnetic phenomena and underlying physical processes. The purpose of the present work is using the IPS-42 ionosonde data and the magnetometer data for a comparative study of the equatorial electrojet parameters.

\subsection{The IPS-42 ionosonde data}

The IPS-42 ionosonde equipments includes an IPS-42 sounder that operates in the frequency range of 1 to $22.6 \mathrm{MHz}$, with an emission power of $5 \mathrm{~kW}$; a delta type antenna oriented in the North-South direction for emission and East-West for reception; and finally a DBD which is a numerical device designed for IPS-42 sounder data processing. These 
equipments have operated at Korhogo $\left(5.43^{\circ} \mathrm{W}, 9.34^{\circ} \mathrm{N},-1.88^{\circ}\right.$ dip-lat) from November 1992 to December 1998 (Vila et al., 1998).

The ionosonde data are sampled by 15 minute time intervals. The data are recorded in form of ionograms. The ionogram exploitation provides the characteristic parameters of the layers of ionosphere, which are respectively their virtual heights $\left(h^{\prime} E, h^{\prime} F 1, h^{\prime} F 2\right)$ and their critical frequencies $\left(f_{o E}, f_{o F 1}\right.$ and $\left.f_{o F 2}\right)$. In this study we use SAO explorer (http://www.ulcar.uml.edu) to analyze the IPS-42 ionosonde data. Note that the SAO explorer is an empirical model, which is mostly used for digisonde data analysis (Abdu et al., 2003; Reinish et al., 2004; Woodman et al., 2006). For the IPS-42 data analysis, the ionograms have been first scaled manually and converted into digisonde data format by using the NHPC software. Then, the converted data can be processed with the SAO explorer to obtain the virtual height of F-layer ( $\left.h^{\prime} F\right)$, the F2 layer critical frequency (foF2), the F2 layer peak height $(h m F 2)$, the Thickness parameter $(B o)$, the shape parameter $(B 1)$ and the plasma scale height (H).

For this study, ionograms of geomagnetic quiet days were selected according to the daily mean values of the geomagnetic activity index $A m$ considered to be lower than $20 \mathrm{nT}$ (Doumouya et al., 1998). In geomagnetic quiet time conditions, 53 days in 1993 and 39 days in 1994, thus a total of 92 days were selected. Figure 3 shows the average daily variations of $h^{\prime} F$ for different seasons in 1993 (Figure 3a, the left column) and 1994 (Figure 3b, the right column). From top to bottom, each panel corresponds to a particular season. March equinox (top row) includes February, March and April; June solstice $\left(2^{\text {nd }}\right.$ row) includes Mai, June and July; September equinox ( $3^{\text {rd }}$ row) includes August, September and October, and finally December solstice (bottom row) includes November, December and January. The dots represent the $h^{\prime} F$ seasonal averages for each 15 minute time interval and the solid curves represent the mean daily variations in different seasons. After a decrease toward a minimum 
around 5:00LT for June and December solstices, the height $h^{\prime} F$ increases from 6:00LT to attain a maximum around 12:00LT; it decreases slowly between 12:00 and 15:00 LT. It briskly increases around 18:00LT before a sharp decrease between 19:00LT and 21:00LT. This evening brisk variation of the $h^{\prime} F$ corresponds to the Pre-Reversal Enhancement (PRE) of the ionospheric zonal electric field (Kelley et al., 2009).

In order to estimate the F-region daytime plasma vertical drift velocity $V_{d}$, we first consider the apparent velocity $\left(V^{\prime}\right)$ to which a correction term $V_{o}$ is added to account for ionization production $(q)$ and recombination loss coefficient $(\beta N)$. The apparent drift velocity $\left(V^{\prime}\right)$ corresponds to the rate of the diurnal variations of the virtual height $h^{\prime} F$ :

$$
V^{\prime}=\frac{d h^{\prime} F}{d t}
$$

The correction term $V_{o}$ is obtained through equation (12) as:

$$
V_{o}=\frac{H \cdot q}{N}-\beta \cdot H
$$

(Iheonu and Oyekola, 2005; Oyekola and Oluwafemi, 2007)

Where $H=\left(N^{-1} \frac{d N}{d h}\right)^{-1}$ is the ionization scale height;

$q(\chi, h)=q_{m, 0} \exp (1-h-\sec \chi \cdot \exp (-h))$ is ionization production rate according to Chapman formula.

$\beta$ is the attachment coefficient calculated using MSIS-E-90 models (Hedin, 1987).

$N=N m F 2 \times \frac{\exp \left(-\chi^{B 1}\right)}{\cosh \chi}$, with $N m F 2=1.24 \times 10^{10}(f o F 2)^{2}$, the maximal density and $\chi=\frac{h_{m} F 2-h}{B_{0}}$, the zenithal angle.

Due to the small dip-latitude of Korhogo ( $-1.88^{\circ}$ dip-lat.) the contributions of the plasma diffusion along the field lines to the F-region daytime vertical drift velocity $V_{d}$ are very small in comparison with the ionization and recombination effects. Thus the diffusion term $(D)$ can be neglected (Iheonu and Oyekola, 2005). 
Finally, the daytime vertical drift velocity $V_{d}$ is determined according to the following relationship:

$V_{d}=\frac{\Delta h^{\prime} F}{\Delta t}+V_{o}$

$V_{d}=\frac{\Delta h^{\prime} F}{\Delta t}+\frac{H \cdot q}{N}-\beta \cdot H$

Where $\Delta h^{\prime} F$ is the F-region virtual height variation over the time interval $\Delta t=15 \mathrm{~min}$.

Bittencourt and Abdu (1981) showed that, after sunset ( $q=0)$, the apparent $F$ layer vertical drift velocity $\left(\frac{\Delta h^{\prime} F}{\Delta t}\right)$ inferred from ionosonde measurements represents the true vertical drift velocity above $300 \mathrm{~km}$. However, below $300 \mathrm{~km}$ the apparent vertical velocity significantly departs from the true vertical drift velocity due to the increasing dominant recombination process at lower altitudes. Those results were also confirmed by Krishna Murthy et al., (1990). This remark was taken into account for the night time drift velocity estimation.

From the F-region daytime vertical drift velocity the zonal electric field can be determined according to Eq. (10). At the magnetic equator, the zonal electric field $\left(\overrightarrow{E_{y}}\right)$ and the geomagnetic field $(\vec{B})$ are both horizontal and perpendicular. Therefore the Plasma vertical drift velocity in the F-region can be expressed as:

$V_{d}=\frac{E_{y}}{B}$

From Eq. 15, $E_{y}$ is determined by:

$E_{y}=B \cdot V_{d}$

The values of the geomagnetic field B are given by the International Geomagnetic Reference Field IGRF-10 model (Macmillan and al., 2003) from the geomagnetic field calculator of website (http://www.ngdc.noaa.gov/geomag-web/\#igrfwmm). For the station of Korhogo, $B=30392 n T$ according to the IGRF-10 model for the epoch 1993.5. 
Note that the Eq. (16) can be obtained at the magnetic dip-equator (inclination $I=0$ ) from the relationship established by Balsley (1973), in which the zonal electric field is expressed as function of the electrons vertical drift velocity, of the geomagnetic field intensity and inclination:

$E_{y}=B \cdot V_{z} \cdot \cos I$

$V_{z}=\overline{V_{d}}$ is the average of the electrons vertical drift velocity.

The polarization electric field is estimated based on Eq. (8). At the dip equator, the zonal electric field $\left(\overrightarrow{E_{y}}\right)$ is perpendicular to the geomagnetic field $(\vec{B})$. Therefore the intensity of the polarization electric field is given by

$E_{p}=\frac{\sum_{H}}{\sum_{P}} \cdot E_{y}$

Where $\sum_{P}$ and $\sum_{H}$ are respectively the integrated Pedersen and Hall conductivities along the field lines. The values of $\sum_{\mathrm{P}}$ and $\sum_{H}$ are estimated through the local conductivities obtained from the International Reference Ionosphere (IRI-2012) model (Bilitza and al, 2012) from the website (http://wdc.kugi.kyoto-u.ac.jp). Figure 4 schematically summarizes the ionosonde data processing method. The first step of this approach consists of estimating the zonal electric field from the ionosonde inferred vertical drift velocity, and the polarization electric field by using integrated Pedersen $\left(\sum_{P}\right)$ and Hall $\left(\sum_{H}\right)$ conductivities. In a second step, various current densities such as Pedersen, Hall and the net eastward EEJ current densities are estimated. Details of various calculations are based on the equations that have been developed in section 2. The integrated peak current density $\left(I_{0}\right)$ at the EEJ center is estimated by height integrating the net eastward EEJ current density.

\subsection{Ground-based magnetic data}

The magnetic stations were designed to collect variations of the $H, D$ and $Z$ components of the geomagnetic field during IEEY campaign. Using these data, Doumouya et 
al. (1998) have estimated the EEJ parameters such as the peak current density, position of the center and the EEJ half-width in a current ribbon assumption. In order to validate the results from ionosonde data by comparison, the EEJ peak current density is estimated from magnetic data using the same method as Doumouya et al. (1998).

The daily regular variations $S_{r}$ of the geomagnetic field are estimated in every station by subtracting values of the night level from the measured field according to the following the relationship:

$S_{r}(t)=B(t)-B_{0}$

Where $\mathrm{B}(\mathrm{t})$ represents the total measured geomagnetic field at a given local time $(\mathrm{t})$ and $\mathrm{B}_{0}$ represents the night level. This night level is the threshold from which the daily regular variation $S_{r}$ rises. It corresponds to the average of the geomagnetic field during the three hours that spans the two local midnights framing the day of interest.

The equatorial electrojet parameters (position of the center, peak current density and halfwidth) can be estimated from the latitudinal profiles of the EEJ contribution to the daily regular variations of the horizontal and vertical components of the geomagnetic field (Figure 5).

The daily regular variation $S_{r}$ includes the mid-latitude $S q$ currents effect and the equatorial electrojet contribution respectively symbolized as $\left(S_{r}^{P}\right)$ and $\left(S_{r}^{E}\right)$ by Fambitakoye and Mayaud (1976). In order to isolate the EEJ effects $S_{r}^{E}$, we remove the $S_{r}^{P}$ from the total $S_{r}$. This approach consists in choosing a threshold from which the EEJ effects start to increase. In that purpose the two stations boarding the meridian chain are considered to be off the EEJ influence area. By interpolating linearly between these stations the $S_{r}^{P}$ is subtracted from the total $S_{r}$ as follows:

$S_{r}^{E}=S_{r}-S_{r}^{P}$

Eq. (20) 
Fambitakoye and Mayaud (1976) have used such an approach with spline interpolation.

Figure 6 presents the diurnal variation of the $S_{R}(H)$ and $S_{r}^{E}(H)$ at the EEJ center. It can be noticed that the differences between the amplitudes of $S_{R}(H)$ and $S_{r}^{E}(H)$ are relatively weak; which means that the EEJ magnetic effect is more important at the dip-equator than that of mid-latitude Sq currents around noon.

From the peak amplitude $\Delta H_{m}$ of the latitudinal profiles of $S_{r}^{E}(H)$ at the EEJ center, we determine the peak current density $I_{0}$ using the following Eq. (21) (Fambitakoye and Mayaud, 1976; Doumouya and al., 1998):

$I_{0}=\frac{\Delta H_{m}}{\left(0.4 \arctan \frac{a}{h}\right)}$

Eq. (21)

Where $h=105 \mathrm{~km}$ is the typical average height of the EEJ, which was established from rocket data (see Fambitakoye and Mayaud, 1976; Doumouya and al., 1998, and references therein), $\boldsymbol{a}$ is the half-width of the EEJ. The half-width is determined according to Eq. (22) after Doumouya et al. (2003):

$a=\sqrt{\frac{d^{2}}{4}-h^{2}}$

Eq. (22)

Where $d$ is the distance between maximum and minimum of latitudinal profiles of the $\mathrm{Z}$ component.

\section{Results}

\subsection{Estimating the plasma vertical drift velocity from ionosonde data}

The plasma vertical drift velocity is estimated by considering (Eq. 14) which takes into account the time rate of the daily variation of the $\mathrm{F}$ layer virtual height $\left(h^{\prime} F\right)$ and the contributions of the photo chemistry that involves the ionization production and recombination factors. 
Figure 7 displays the daily variation of the mean vertical drift velocity in different seasons in 1993 (Figure 7a, left column) and 1994 (Figure 7b, right column). The dots represent the seasonal averages for each 15 minutes time interval and the solid curves represent the mean daily variations in different seasons. The patterns of the plasma vertical drift velocity average daily variation are roughly similar in all seasons. In March and September equinoxes, it decreases between 0:00 and 4:00LT toward minimum values that attains $-20 \mathrm{~m} / \mathrm{s}$. From about 6:00LT to $15: 00 \mathrm{LT}$ variations of the drift velocity are small, and exhibit quasi flat variations between about 8:00 and 15:00LT in all the seasons except for September equinox, for which a sort of dome is observed in this time interval with a maximum between about 10:00LT and 11:00LT. After 15:00LT, the drift velocity sharply increases toward a maximum that attains 40m/s around 19:00LT in March equinox in 1993. This increase, known as evening "Pre Reversal Enhancement (PRE)" (Kelley et al., 2009), is also followed by a sharp decrease toward negative values, with a minimum peak of about $35 \mathrm{~m} / \mathrm{s}$ around 21:00LT in all the seasons.

\subsection{Estimating the zonal and polarization electric fields from ionosonde data}

As one of the purposes of the present study is estimating parameters of the EEJ, a daytime ionospheric current with the maximum flow around noon, our efforts are concentrated on noontime variations of the plasma vertical drift velocity. Thus for this study, the monthly mean values of the vertical drift velocity around 12:00LT are considered to estimate the daytime zonal electric field intensity $\left(E_{y}\right)$ according to Eq. 16. Variations of $E_{y}$ monthly means from January 1993 to December 1994 are shown in Figure 8a. The dots correspond to the monthly averages of $E_{y}$ and the error bars represent the standard deviations. This figure shows that the zonal electric field intensity varies according to the seasons. It is stronger in equinoxes than in solstices (Table 2). On the average, the zonal electric field intensity is comprised between $0.43 \mathrm{mV} / \mathrm{m}$ and $0.49 \mathrm{mV} / \mathrm{m}$ during the considered period. The 
seasonal average values of diverse parameters estimated from the monthly means in the time interval between 10:00 and 14:00LT are shown in Table 2.

Based on Eq. 18, the intensities of polarization electric field $\left(E_{p}\right)$ were estimated from the corresponding zonal electric field intensities. Figure $\mathbf{8 b}$ shows variations of $E_{p}$ from January 1993 to December 1994 . The dots correspond to the monthly averages of $E_{p}$ and the error bars represent the standard deviations. The polarization field intensity exhibits the same seasonal trend as the zonal electric field. It is also stronger in equinoxes than in solstices. However the polarization field intensities are found to be about 18 times stronger than that of corresponding zonal electric field. Alken and Maus (2010) found the same results in the American sector. On the average, the polarization electric field intensity is comprised between $7.63 \mathrm{mV} / \mathrm{m}$ and $9.51 \mathrm{mV} / \mathrm{m}$ during the considered period. The seasonal averages of the zonal and vertical polarization electric fields around 12:00LT are shown in Table 2 together with the plasma vertical drift velocity.

\subsection{Estimating the ionospheric current densities from ionosonde data}

In the narrow dip-latitude band of $\pm 3^{\circ}$ across the dip-equator, when the total vertical current is cancelled around the local noon, only the horizontal eastward Pedersen (Eq. 1) and the Hall currents (Eq. 4) remain (Richmond, 1995, Onwumechili, 1997). Using the monthly values of the zonal and vertical polarization electric fields estimated in the previous section, the eastward Pedersen $\left(J_{P 1}\right)$ and Hall $\left(J_{H 2}\right)$ current densities and the total eastward current density $\left(J_{E E J}\right)$ have been estimated at $105 \mathrm{~km}$. Figure 9 presents variations of $J_{P 1}$ (Figure 9a), $J_{H 2}$ (Figure 9b) and $J_{E E J}$ (Figure 9c) from January 1993 to December 1994. The dots correspond to the monthly averages of the current densities and the error bars represent the standard deviations. The three current densities exhibit the same trend of seasonal variations. However it is to be noticed that the amplitude of the eastward Pedersen current density is 
about 300 times weaker than the eastward Hall current density. During the two years the amplitude of $J_{P 1}$ varies approximately between $12.10^{-3} \mathrm{~A} / \mathrm{km}^{2}$ and $16.10^{-3} \mathrm{~A} / \mathrm{km}^{2}$, while $J_{H 2}$ is comprised between $3.63 \mathrm{~A} / \mathrm{km}^{2}$ and $5.80 \mathrm{~A} / \mathrm{km}^{2}$. The yearly mean values of the eastward Pedersen current density are respectively $(15.1 \pm 2.3) \cdot 10^{-3} \mathrm{~A} / \mathrm{km}^{2}$ in 1993 and (13.3 \pm 1.9$) .10^{-3}$ $\mathrm{A} / \mathrm{km}^{2}$ in 1994 , and that of the Hall current density are $(4.98 \pm 0.98) \mathrm{A} / \mathrm{km}^{2}$ in 1993 and (4.45 $\pm 0.75) \mathrm{A} / \mathrm{km}^{2}$ in 1994 . As consequence, the eastward Pedersen current density appears to be negligible with respect to the eastward Hall current density. Thus the equatorial electrojet current density $\left(J_{E E J}\right)$ in Figure $9 \mathrm{c}$ appears to be in the same order as the eastward Hall current density.

\subsection{Estimating the EEJ peak current density from ionosonde data}

Assuming the equatorial electrojet as a thin current ribbon that circulates at $105 \mathrm{~km}$ altitude, the integrated peak current density $\left(I_{0}\right)$ at its center can be considered as a proxy of the EEJ strength (Fambitakoye, 1976, Doumouya et al., 1998). In order to evaluate the electric fields and current densities determined in the previous sections, an estimate of the integrated peak current density $\left(I_{0}\right)$ is made in this section. Thus EEJ current density $J_{E E J}$ was integrated over the thickness of the E-layer. In this purpose a uniform height distribution of $J_{E E J}$ was assumed. Thus $I_{0}$ was obtained by multiplying $J_{E E J}$ times the mean thickness $\left(e_{E}\right)$ of the Elayer (Eq. 23).

$I_{0}=J_{E E J} \cdot e_{E}$ Eq. (23)

The E layer thickness $\left(e_{E}\right)$ is approximately estimated between $90 \mathrm{~km}$ and $140 \mathrm{~km}$ altitudes, that is $e_{E}=50 \mathrm{~km}$

The EEJ peak current density $\left(I_{0}\right)$ at the center is usually estimated from EEJ magnetic variations observed at the dip-equator (Fambitakoye, 1976, Doumouya et al., 1998). In order to validate ionosonde inferred electrodynamics parameters, the EEJ peak current density $\left(I_{0}\right)$ 
was estimated from ground-based magnetic data recorded during the same time period according to (Eq. 21). In the next section the EEJ integrated peak current densities $\left(\boldsymbol{I}_{\mathbf{0}}\right)$ obtained from ionosonde data are compared with that inferred from magnetic data.

\subsection{Comparison between parameters inferred from magnetometer and ionosonde data.}

In this section correlation between the EEJ magnetic effect and the vertical $\vec{E} \times \vec{B}$ drift velocity is examined, and the EEJ integrated peak current densities estimated from ionosonde magnetic data are compared. Figure 10 shows a fairly good linear correlation between the peak amplitude of the EEJ magnetic effect $(\Delta H)$ at the EEJ center and the vertical drift velocity $V_{d}$, with a correlation coefficient $\mathrm{R}=0.74$.

Figure 11 compares the seasonal averages of the EEJ integrated peak current density estimated from ionosonde data (red circles) and magnetic data (black dots). The seasonal averages of the integrated peak current density $\left(I_{0}\right)$ obtained from ionosonde data $\left(\boldsymbol{I}_{\mathbf{0} i}\right)$ are given in Table 2. According to Figure 11 the values of $\boldsymbol{I}_{\mathbf{0} \boldsymbol{i}}$ are higher than that of $\boldsymbol{I}_{\mathbf{0} \boldsymbol{m}}$ in most cases. The highest difference between $\boldsymbol{I}_{\mathbf{0} \boldsymbol{i}}$ and $\boldsymbol{I}_{\mathbf{0} \boldsymbol{m}}$ is $62.97 \mathrm{~A} / \mathrm{km}$. This value is larger than the standard deviations of $45 \mathrm{~A} / \mathrm{km}$ obtained in previous studies by Doumouya et al. (1998). However, the results from both experiments are relatively close. The root-mean-square (rms) deviation between $\boldsymbol{I}_{\mathbf{0} \boldsymbol{i}}$ and $\boldsymbol{I}_{\mathbf{0} \boldsymbol{m}}$ is $15.91 \mathrm{~A} / \mathrm{km}$. Furthermore $\boldsymbol{I}_{\mathbf{0} \boldsymbol{i}}$ and $\boldsymbol{I}_{\mathbf{0} \boldsymbol{m}}$ remarkably exhibit similar trend for the seasonal variability, with maxima during the equinoxes and minima during the solstices. In addition, the effects of the decreasing phase of the solar cycle between 1993 and 1994 can be noticed as well.

\section{Discussion and conclusion}

In the present work, some characteristic parameters of the equatorial electrojet have been estimated on the basis of the IPS-42 ionosonde data at Korhogo. The results have been compared with that obtained from magnetic data. This study consisted of determining the 
zonal electric field through an estimate of the plasma vertical $E \times B$ drift velocity from ionosonde data. In that purpose, the apparent plasma vertical drift velocity $\left(V^{\prime}\right)$ that corresponds to the time rate of the diurnal variations of the F-layer virtual height, and the photo chemical effects that include the ionization production and recombination were considered. Note that in most studies, the F-layer vertical drift velocity was estimated by the time rate of the F-layer virtual height during periods of dominant electric convection like the pre-reversal enhancement (Abdu et al., 1981, 2004, 2006; Batista et al., 1986; Subbarao and Krishna Murthy, 1993; Hari and Krishna Murthy, 1995; Batista et al., 1996; Bittencourt and Abdu., 1981; Oyekola and Oluwafemi, 2007; Adebesin et al., 2013). For the present study, we estimated the photo chemical effects according to the approach used by Iheonu and Oyekola (2005) and Oyekola and Oluwafemi (2007). It is to be noticed that this approach significantly improved the estimated daytime F-layer plasma vertical drift velocity.

The trend of the daily variation of the plasma vertical drift velocity is roughly same as that obtained from previous studies by Bonelli and Carvalho, 1993; Batista et al., 1996; Scherliess and Fejer (1999); G. Li et al (2007). Indeed, the main features such as the prereversal enhancement around 19:00 are also observed in Figure 7. The day-time dome with a maximum around 12:00 is observed in all seasons as that obtained by Scherliess and Fejer (1999) and G. Li et al (2007). The noontime averages of the drift velocity shown in Table 2 vary according to seasons. They are higher in equinoxes than in solstices. For all the seasons the noontime average values of the vertical drift velocity at Korhogo range $13.56 \mathrm{~m} / \mathrm{s}$ and $15.61 \mathrm{~m} / \mathrm{s}$ Anderson et al. (2006) estimated the vertical drift velocity in 3 longitude sectors from January 2001 to December 2004. They found a minimum value of $10 \mathrm{~m} / \mathrm{s}$ in equinox and maximum values that attain $25 \mathrm{~m} / \mathrm{s}$. According to Figure 1 of $\mathrm{Li}$ et al (2007), based on satellite ROCSAT-1 observations in 5 longitude sectors and different seasons in period 2000-2002, the values of the daytime vertical drift velocity also range between about $10 \mathrm{~m} / \mathrm{s}$ to $30 \mathrm{~m} / \mathrm{s}$. Our 
results range well in the intervals of Anderson et al. (2006) and Li et al (2007). However, possible differences between our result and that obtained by Anderson et al. (2006) and Li et al (2007) can be explained by the dependence of the vertical drift velocity on the longitudes, and also on the solar cycle. Indeed the period 1993-1994 was in the decreasing phase close to the end minimum of the solar cycle 22. In contrast, the studies of Anderson et al. (2006) and Li et al (2007) concerned the period which included the maximum of solar cycle 23.

The seasonal average values of the zonal electric field range $0.47 \mathrm{mV} / \mathrm{m}$ and $0.46 \mathrm{mV} / \mathrm{m}$ during the period 1993-1994, in West Africa. The estimated zonal electric field, the IRI-2012 model ionospheric conductivities, and the IGRF-10 model geomagnetic field intensity have been used to estimate the vertical polarization electric field $\left(\overrightarrow{E_{p}}\right)$, the eastward Pedersen $\left(\overrightarrow{J_{p 1}}\right)$ and Hall $\left(\overrightarrow{J_{H 2}}\right)$ current densities, and the net eastward EEJ current density $\left(\overrightarrow{J_{E E J}}\right)$. By height integrating the net eastward EEJ current density between $90 \mathrm{~km}$ and $140 \mathrm{~km}$ altitudes, the integrated peak current density $\left(I_{0}\right)$ at the EEJ center has been estimated as well. In order to evaluate the method of estimating these parameters, the IPS-42 ionosonde based integrated peak current density $\left(I_{0 i}\right)$ has been compared with that obtained from ground-based magnetic observations $\left(I_{0 m}\right)$. The values obtained from the two methods are found to be in the same order. In addition, their seasonal variations and dependence on the solar activity are found to be similar.

This study has shown that more basic parameters of the equatorial electrojet can be accessible with a good accuracy, if the daytime F-region plasma vertical drift velocity can be accurately estimated. Unfortunately, in contrast of the American sector with the Jicamarca VHF radar, the lack of VHF radar continuous measurements near the dip equator in the African longitude sectors, does not allow such study. The HF radar used at Korhogo during the IEEY (Blanc and Houngninou, 1998) operated only from March to July, 1993. 


\section{Acknowledgement}

The IPS-42 ionosonde was operated by the Centre National d'Etude de Télécommunication (CNET) France and the network of 10 magnetic stations by ORSTOM (now IRD) during the International Equatorial Electrojet Year (IEEY). The student Franck Oswald Grodji has received a grant from the Government of Cote d'Ivoire for his $\mathrm{PhD}$ study.

\section{References}

Abdu, M.A., Bittencourt, J. A., Batista, I.S.: Magnetic declination control of the equatorial F regin dynamo electric field development and spread F. J. Geophys. Res. 86, 11443-11446, 1981.

Abdu, M.A., Batista, I.S., Reinisch, B.W., de Souza, J.R., de Paula, E.R., Sobral, J.H.A and Bullett, T. W.: Equatorial Spread F and Ionization Anomaly development as diagnosed from conjugate point observation (COPEX) in Brasil, in: XXIII General Assembly of IUGG (International Union of Geodesy and Geophysics), Sapporo, Japan, 30 de Junho a 11 de Julho de, 2003.

Abdu, M., Batista, I. S., Reinisch, B. W., Carrasco, A. J.: Equatorial F layer heights, evening prereversal electric field, and night E-layer density in the American sector. IRI validation with observations. Adv. Space Res. 34, 1953-1965, 2004.

Abdu M.A., Batista, I.S., Reinisch, B.W., Sobral, J.H.A and Carrasco, A.J.: Equatorial F region evening vertical drift, and peak height, during southern winter months: A comparison of observational data with the IRI descriptions, Adv. Space Res. 37, 1007-1017, 2006.

Adebesin, B. O., Adeniyi, J. O., Adimula, I. A., and Reinisch, B. W.: Equatorial vertical plasma drift velocities and electron densities inferred from ground ionosonde measurements during low solar activity, J. of Atmos. and Sol. Terr. Phys., 97, 58-64, 2013.Alken, P and Maus, S.: Spatio- 
temporal characterization of the equatorial électrojet from CHAMP, Ørsted, SAC-C satellite magnetic measurements, J. Geophys. Res, 112,A09305, doi: 1029/2007 JA012524, 2007.

Amory-Mazaudier C., Achache, J., Achy-Seka, A., Albouy, Y., Blanc, E., Boka, K., Bouvet, J., Cohen, Y., Diatta, C-S., Doumouya, V., Fambitakoye, O., Gendrin, R., Goutelard, C., Hamoudi, M., Hanbaba, R., Hougninou, E., Huc, C., Kakou , K., Kobea Toka , A., LassudrieDuchene, P., Mbipom, E., Menvielle, M., Ogunade, S.O., Oyinloye, J. O., Rees, D., Richmond, A., Sambou, E., Schmucker, E., Tireford, J. L., Vassal, J., Vila. P.: International Equatorial Electrojet Year, Brazilian journal of Geophysics, Vo1. 11 (3), pp 303-317, special issue, invited paper, 1993.

Anderson, D., Anghel, A., Chau, J. L and Yumoto, K.: Global, low-latitude, vertical ExB drift velocities inferred from day-time magnetometer observations, Space weather. 4. S08003, doi: 10, 1029/2005 SW00193, 2006.

Anderson. D., Anghel, A., Chau, J and Velez, O.: Daytime vertical ExB drift velocities inferred from ground-based magnetometer observations at low latitudes, space weather 2, s 11001, doi:10.1029/2004 SW000095, 2004.

Anderson. D., Anghel. A., Yumoto, K., Ishitsuka, M and Kudeki, E.: Estimating day-time vertical ExB drift velocities in the equatorial F-region using ground-based magnetometer observations, Geophysics. Res. Let, vol. 29, no. 12, p. 31(1)-37(4), 2002.

Baker, W. G and Martyn, D. F.: Electric current in the ionosphere, I- The conductivity, Phil. Trans. Roy. Soc. London A. 245, 251-294, 1953.

Balsley, B.: Electric field in the equatorial ionosphere: a review techniques and measurements, J. of Atmos. and Sol. Terr. Phys., 35, p.1035-1044, 1973. 
Bartels, J. and H.,F., Johnston: Some features of the large geomagnetic tides in the horizontal force at Huancayo. Trans. Amer. Geophys. Union, p. 273-287, 1940

Batista, I.S., Abdu, M.A and Bittencourt, J.A.: Equatorial F-region vertical plasma drifts: Seasonal and longitudinal asymmetries in the American sector. J. Geophys. Res. 91, 12055$12064,1986$.

Bilitza, D., Brown, S. A., Matthew, Y. W., Jonas, R. S and Patrick, A. R.: Measurements and IRI model predictions during the recent solar minimum, J. of Atmos. and Sol. Terr. Phys., 86. 99106, doi: 10. 1016/j.jastp 2012. 06.010, 2012.

Bittencourt, J.A., Abdu, M.A.: A theoretical comparison between apparent and real vertical ionization drift velocities in the equatorial F-region. J. Geophys. Res. 86, 2451-2455, 1981.

Blanc, E and Houngninou, E.: Typical disturbances of the daytime equatorial $\mathrm{F}$ region observed with a high-resolution HF radar, Ann. Geophysical 16, 721-730, 1998.

Cain, J. C and Sweeney, R. E.: The POGO data, J. of Atmos. and Sol. Terr. Phys., 35, 12311247, 1973.

Chapman, S.: The equatorial electrojet as detected from the abnormal electric current distribution above Huancayo, Peru and Elsewhere. Arch. Meteorol. Geophys. Bioclimatol A 44, P 368-390, 1951.

Coley, W. R and Heelis, R. A.: Low-latitude zonal and vertical ion drifts seen by DE2, J. Geophys. Res., 94, 6751-6761, 1989.

Coley, W. R., McClure, J. P and Hanson, W. B.: Equatorial fountain effect and dynamo drift signatures from AE-E observations, J. Geophys. Res., 95, 21,285-21,290, 1990. 
Cowling, T. G.: The electrical conductivity of an ionized gas in the presence of a magnetic field, Mon, Not. R. Astron. Soc., 93, 90-98, 1933.

Doumouya, V., Vassal, J., Cohen, Y., Fambitakoye, $\mathrm{O}$ and Menvielle, M.: The equatorial électrojet at African Longitudes: First result from magnetic measurement, Ann. Geophys, 16, P. 658-676, 1998.

Doumouya, V., Cohen, Y., Arora, B and Yumoto, K.: Local time and longitude dependence of the equatorial electrojet magnetic effects, J. of Atmos. and Sol. Terr. Phys., 65, 1265-1282, 2003.

Doumouya, V and Cohen, Y.: Improving and testing the empirical equatorial electrojet model with CHAMP satellite data, Ann. Geophys., 22, 3323, 2004.

Fambitakoye, $\mathrm{O}$ and Mayaud, P. N.: The equatorial electrojet and regular daily variation $\mathrm{S}_{\mathrm{R}}$ : I. A determination of the equatorial electrojet parameters, J. of Atmos. and Sol. Terr. Phys., 38, 1-17, 1976.

Farley, D. T., Balsley, B. B., Woodman, R. F and McClure, J. P.: Equatorial spread F: Implication of VHF radar observation, J. Geophys. Res., 75, 7199-7216, 1970.

Fejer, B. G., de Paula, E. R., Gonzales, S. A and Woodman, R. F.: Average vertical and zonal Fregion plasma drifts over Jicamarca, J. Geophys. Res., 96, 13901-13906, 1991.

Fejer, B. G., de Paula, E. R., Heelis, R. A and Hanson, W. B.: Global equatorial ionospheric vertical plasma drifts, J. Geophys. Res., 100, 5769-5776; 1995.

Fejer, B., Scherliess, L and de Paula, E.R.: Effects of the vertical plasma drift velocity on the generation and evolution of equatorial spread $F, J$. Geophys. Res. 104 (A9), 19859-19869, 1999. 
Forbush, S and Casaverde, M.: The Equatorial electrojet in Peru. Carnegie institute. Washington. Publ. 620, 1961.

Goel, M. K., Singh, S. S and Rao, B. C. N.: Post-sunset rise of F-layer height in the equatorial region and its relation to the F-layer dynamo polarization fields, J. Geophys. Res., 95, 6237$6246,1990$.

Hari, S. S and Krishna Murthy, B. V.: Equatorial night-time f-region zonal electric fields, Ann. Geophysicae 13, 871-878, 1995.

Hedin, A. E.: MSIS-87 thermospheric model, J. Geophys. Res., 92, 4649-4662, 1987.

Heelis, R. A and Coley, W. R.: East-west drifts at midlatitudes observed by dynamics explorer 2, J. Geophys. Res., 97, 19,461-19,469, 1992.

Hesse, D. An investigation of the equatorial electrojet by mean of ground-based magnetic measurements in Brazil, Ann. Geophys., 87, 315-320, 1982.

Iheono, E. E and Oyekola, O. S.: vertical drift velocity in the dayetime F-region at Ibadan estimated from ionosonde data. Indian journal of radio \& space physics. Vol. 35, 9-13, 2006.

Jadhav, G. Rajaram, M and Rajaram, R.: A Detailed study of equatorial electrojet phenomenon using Ørsted satellite observations, J. Geophys. Res., 107(A8), 1175, doi: 10. 1029/2001JA000183, 2002.

Krishna Murthy, B. V., Hari, S. S and Somayajulu, V. V.: Night-time equatorial thermospheric meridional winds from ionospheric h'F data, J. Geophys. Res., 95, 4307-4310, 1990. 
Le Mouel, J. L., Shebalin, P and Chuliat, A.: The field of the equatorial electrojet from CHAMP data, Ann. Geophys., 24,515-527, 2006.

Lühr, H., Maus, S and Rother, M.: Noon-time equatorial electrojet: Its spatial features as determined by the CHAMP satellite, J. Geophys. Res., 109, A01306, doi: 10.1029/2002JA009656, 2004.

Macmillan, S., Maus, S and Bondar, T.: Ninth generation International Geomagnetic Reference Field Released, EOS transaction, AGU, volume 84, Issue 46,503-503, 2003 and Geophys. J. Int., 155, 1051-1056 , 2003. (http://www.ngdc.noaa.gov/geomag-web/\#igrfwmm).

Martyn, D.: Electric conductivity of the ionospheric D-region, nature, 162, P. 142-143, 1948.

Namboothiri, S. P., Balan, N and Rao, P. B.: Vertical plasma drifts in the F-region at magnetic equator, J. Geophys. Res., 94, 12055-12060, 1989.

Ning, G., Li, B., Liu, L., Ren, Z., Lei, J and Su, S. Y.: The correlation of longitudinal/seasonal variations of evening equatorial pre-reversal drift and of plasma bubbles, Ann. Geophys., 25, 2571-2578, 2007.

Onwumechili, C. A. The Equatorial Electrojet, Gordon and Breach Science Publishers, 1997.

Onwumechili, C. A.: Geomagnetic variation in the equatorial zone, physics of Geomagnetic phenomena-I, Acad. Press, New York and London, 425-507,1967.

Onwumechili, C. A and Agu, C. E.: Longitude variation of equatorial parameters derived from POGO satellite observations, Planet. Space Sci., 29, 627-634, 1981.

Oyekola, S. O., Oluwafemi, O. C.: Morphology of F-region vertical $E \times B$ drifts in the African sector using ionosonde measurements. Annals of Geophysics 50, 615-625, 2007. 
Rabiu, A.B., Onwumechili,C.A., Nagarajan, N., Yumoto, K. Characteristics of equatorial electrojet over India determined from a thick current shell model. J. of Atmos. and Sol. Terr. Phys., 92, 105- 115. 10.1016/j.jastp.2012.10.014, 2013

Redmon, R. J., Anderson, D., Caton, R and Bullett T.: A Forecasting Ionospheric Real-time Scintillation Tool (FIRST), Space Weather, 8, S12003, doi:10.1029/2010SW000582, 2010.

Reinisch, B.W., Abdu, M.A., Batista, I.S., Chau, J., Rios, V., Bullett, T. Multi-station equatorial spread F digisonde observations in South America. Ann. Geophys. 22, 3145-3153, 2004.

Richmond, A.D., Ionospheric Electrodynamics. In: Volland H. (Ed.), Handbook of Atmospheric Electrodynamics, Vol. II, pp. 249-290. CRC press, Boca Raton, Florida, 1995.

Richmond, A. D., Blanc, M., Emery, B. A., Wand, R. H., Fejer, B. G., Woodman, R. F., Ganguly, S., Amayenc, P., Behnke, R.A., Calderon, C and Evans, J.V.: An empirical model of quiet-day ionospheric electric fields at middle and low latitudes, J. Geophys. Res., 85 (A9), 4658-4664, 1980.

Sampath, S and Sastry, T.: Results from "in situ" measurements of ionosphere currents in the equatorial zone, J. Geomg. Geoelectr, 31. 373-379, 1979.

Scherliess, L and Fejer, B. G.: Radar and satellite global equatorial F-region vertical drift model, J. Geophys. Res., 104(A4), 6829-6842, 1999.

Sugiura. M and Cain, J. C.: A model equatorial electrojet, J. Geophys. Res. 71, 1966

Vassal, J. Menvielle, M. Cohen, Y. Dukhan, M. Doumouya, V. Boka, K and Fambitakoye. O.: A study of transient variations in the earth's electromagnetic field at equatorial electrojet latitudes in western Africa (Mali and Ivory Coast). Vol. 16, 677-697, 1998. 
Vila, P., Rees, D., Merrien, P and Kone, E.: Fabry-Perot interferometer measurements of neutral winds and F2 layer variations at the magnetic equator, Ann. Geophys., vol. 16, 731-737, 1998.

Woodman, R. F.: Vertical drift velocities and east-west electric field at the magnetic equator, J. Geophys. Res., 75, 6249-6259, 1970. 


\section{Figure captions}

Figure 1: Mechanism of the equatorial electrojet current flow in the E-region is described in three steps. Step 1: zonal electric Ey (red arrow), magnetic field B (green cross-circle), downward Hall current density (dashed wide arrow) and the eastward Pedersen current (solid wide arrow). Step 2: vertical polarization electric Ep (blue arrow), magnetic field B (green cross-circle), upward Pedersen current density (dashed wide blue arrow) and the eastward Hall current density (solid wide blue arrow). Step 3: The total EEJ current density (wide pink arrow).

Figure 2: The $5^{\circ} \mathrm{W}$ meridian chain magnetic stations (asterisk) and the ionosonde (triangle) installed in West Africa during the International Equatorial Electrojet Year (IEEY).

Figure 3: Daily trend of the F layer virtual heights $h^{\prime} F$ from the ISP-42 ionosonde data in 1993 (a) and 1994 (b). The dots indicate the seasonal average of the F layer virtual height at every 15 minutes and the solid lines represent the hourly averages.

Figure 4: diagrams of the method used to process ionosonde data for the estimation of the electric fields and current densities of the equatorial ionosphere in West Africa.

Figure 5: Latitudinal profiles of the regular daily variation $\mathrm{Sr}$ of the $\mathrm{D}, \mathrm{H}$ and $\mathrm{Z}$ components of the geomagnetic field, on 24 February 1993.

Figure 6: Daily regular variation of the horizontal component $(\mathrm{H})$ of the geomagnetic field. The dashed red lines represent the total daily regular variation $S_{r}(H)$, and the solid blue lines represent the equatorial electrojet contribution $S_{r}^{E}(H)$ in the daily regular variation $S_{r}(H)$.

Figure 7: Daily variation of the vertical drift velocity from the ISP-42 ionosonde data in different seasons of 1993 (a) and 1994 (b). The dots indicate the seasonal averages of the vertical drift velocity at every 15 minutes and the solid lines represent the hourly averages. 
Figure 8: Seasonal variations of the Zonal electric field $E_{y}$ (a) and Polarization electric field $E_{P}$ (b). The dots represent the monthly averages of $E_{y}$ respectively $E_{P}$ from January 1993 to December 1994, the error bars indicate the standard deviations.

Figure 9: Variation of the eastward Pedersen (a), Hall (b) and total electrojet (c) current densities obtain from the IPS-42 ionosonde data during the two years (1993 and 1994).

Figure 10: Correlation between the EEJ magnetic effect $\Delta H$ and the vertical drift velocity $V_{d}$

Figure 11: Comparison of the peak current density $\left(I_{0}\right)$ of the equatorial electrojet obtained from the IPS-42 ionosonde data (red circles $\boldsymbol{I}_{\mathbf{0} \boldsymbol{i}}$ ) and magnetometer data (black dots $\boldsymbol{I}_{\mathbf{0} \boldsymbol{m}}$ ).

\section{List of tables}

Table 1: Geographic coordinates of the magnetic stations installed along the meridian $5^{\circ} \mathrm{W}$ in West Africa during the International Equatorial Electrojet Year.

Table 2: Seasonal averages of the plasma vertical drift velocity $\left(V_{d}\right)$, the zonal $(E y)$ and polarization $(E p)$ electric fields, the eastward Pedersen $\left(J_{P}\right)$ and Hall $\left(J_{H}\right)$ current densities, and the net eastward current density $\left(J_{E E J}\right)$ between 10:00LT and 14:00LT in 1993 and 1994. 
Table 1 : Geographic coordinates of the magnetic stations installed along the meridian $5^{\circ} \mathrm{W}$ in West Africa during the International Equatorial Electrojet Year.

\begin{tabular}{|l|c|c|c|c|}
\hline \multirow{2}{*}{ Stations } & \multirow{2}{*}{ Code } & \multicolumn{2}{c|}{ Geographic } & \multirow{2}{*}{ Dip Lat.( ${ }^{\circ}$ ) } \\
\cline { 2 - 5 } & & Lat $\left({ }^{\circ} \mathbf{N}\right)$ & Long $\left({ }^{\circ} \mathbf{W}\right)$ & \\
\hline Tombouctou & Tom & 16.733 & 3.000 & 6.76 \\
\hline Mopti & Mop & 14.508 & 4.087 & 4.02 \\
\hline San & San & 13.237 & 4.879 & 2.45 \\
\hline Koutiala & Kou & 12.356 & 5.448 & 1.38 \\
\hline Sikasso & Sik & 11.344 & 5.706 & 0.12 \\
\hline Nielle & Nie & 10.203 & 5.636 & -1.30 \\
\hline Korhogo & Kor & 9.336 & 5.427 & -1.88 \\
\hline Katiola & Kat & 8.183 & 5.044 & -3.85 \\
\hline Tiebissou & Tie & 7.218 & 5.241 & -5.04 \\
\hline Lamto & Lam & 6.233 & 5.017 & -6.30 \\
\hline
\end{tabular}


Table 2: Seasonal averages of the plasma vertical drift velocity $\left(V_{d}\right)$, the zonal $(E y)$ and polarization $(E p)$ electric fields, the eastward Pedersen $\left(J_{P}\right)$ and Hall $\left(J_{H}\right)$ current densities, the net eastward current density $\left(J_{E E J}\right)$ and the peak current density $\left(I_{0 i}\right)$ at the center of the equatorial electrojet around noontime in 1993 and 1994.

\begin{tabular}{|c|c|c|c|c|c|c|c|c|}
\hline & \multicolumn{4}{|c|}{1993} & \multicolumn{4}{|c|}{1994} \\
\hline & M. Eq & J. Sol & S. Eq & D. Sol & M. Eq & J. Sol & S. Eq & D. Sol \\
\hline$V_{d}(\mathrm{~m} / \mathrm{s})$ & 15.61 & 15.01 & 15.30 & 13.81 & 15.03 & 14.01 & 15.01 & 13.56 \\
\hline Ey $(\mathrm{mV} / \mathrm{m})$ & 0.49 & 0.47 & 0.48 & 0.44 & 0.48 & 0.47 & 0.48 & 0.43 \\
\hline$E p(\mathrm{mV} / \mathrm{m})$ & 9.51 & 8.41 & 8.98 & 7.61 & 9.22 & 7.93 & 8.81 & 7.63 \\
\hline$J_{P I}\left(10^{-3} \mathrm{~A} / \mathrm{km}^{2}\right)$ & 15.8 & 16.3 & 15.3 & 13.0 & 13.6 & 13.6 & 14.0 & 11.7 \\
\hline$J_{H 2}\left(\mathrm{~A} / \mathrm{km}^{2}\right)$ & 5.80 & 5.02 & 5.19 & 3.90 & 5.06 & 4.35 & 4.75 & 3.63 \\
\hline$J_{E E J}\left(\mathrm{~A} / \mathrm{km}^{2}\right)$ & 5.82 & 5.04 & 5.21 & 3.92 & 5.07 & 4.36 & 4.76 & 3.64 \\
\hline Ioi $(\mathrm{A} / \mathrm{km})$ & 290.80 & 252.03 & 260.55 & 196.12 & 253.93 & 218.43 & 238.68 & 182.14 \\
\hline
\end{tabular}




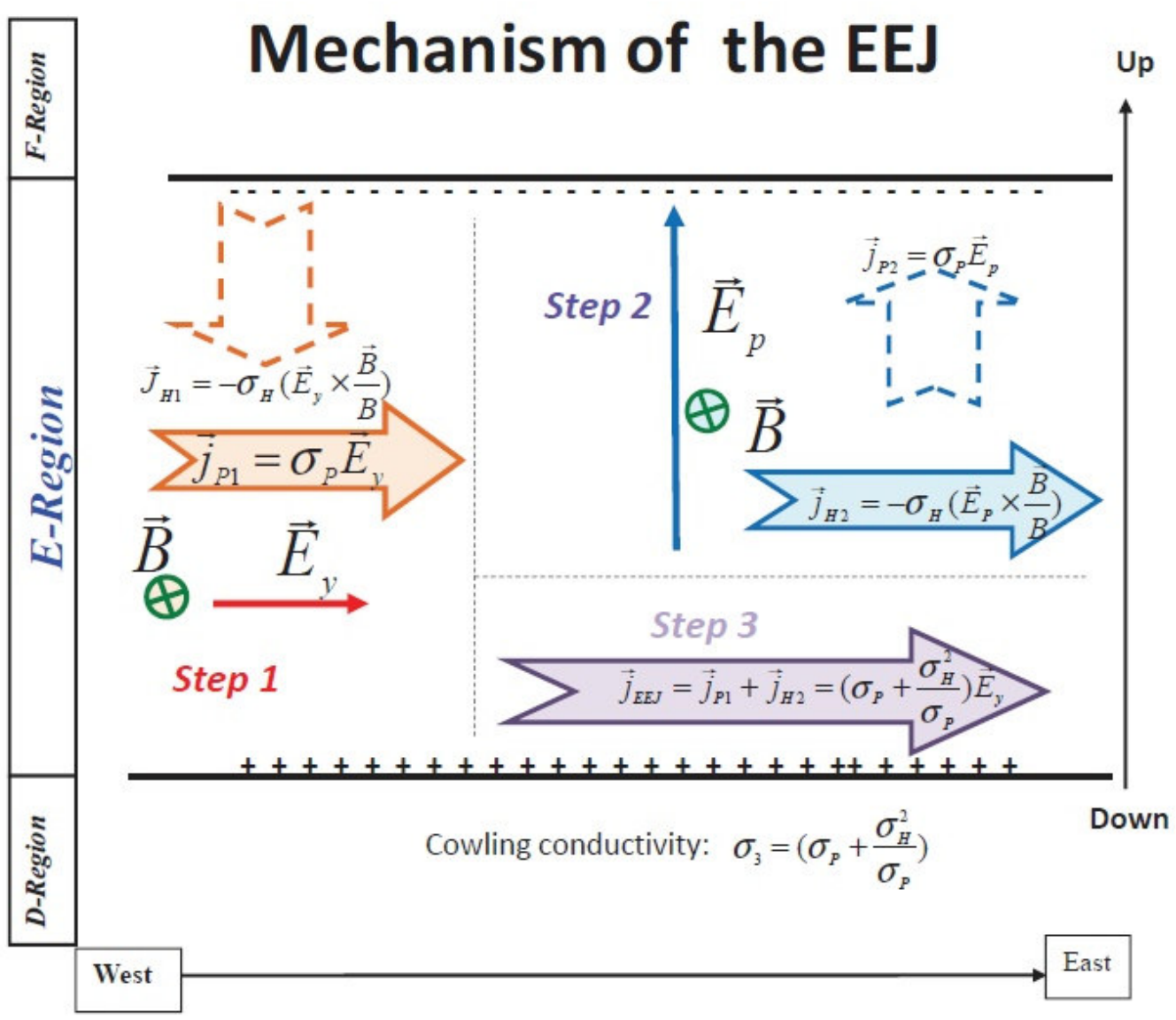

Figure 1: Mechanism of the equatorial electrojet current flow in the E-region is described in three steps. Step 1: zonal electric Ey (red arrow), magnetic field B (green cross-circle), downward Hall current density (dashed wide arrow) and the eastward Pedersen current (solid wide arrow). Step 2: vertical polarization electric Ep (blue arrow), magnetic field B (green cross-circle), upward Pedersen current density (dashed wide blue arrow) and the eastward Hall current density (solid wide blue arrow). Step 3: The total EEJ current density (wide pink arrow). 


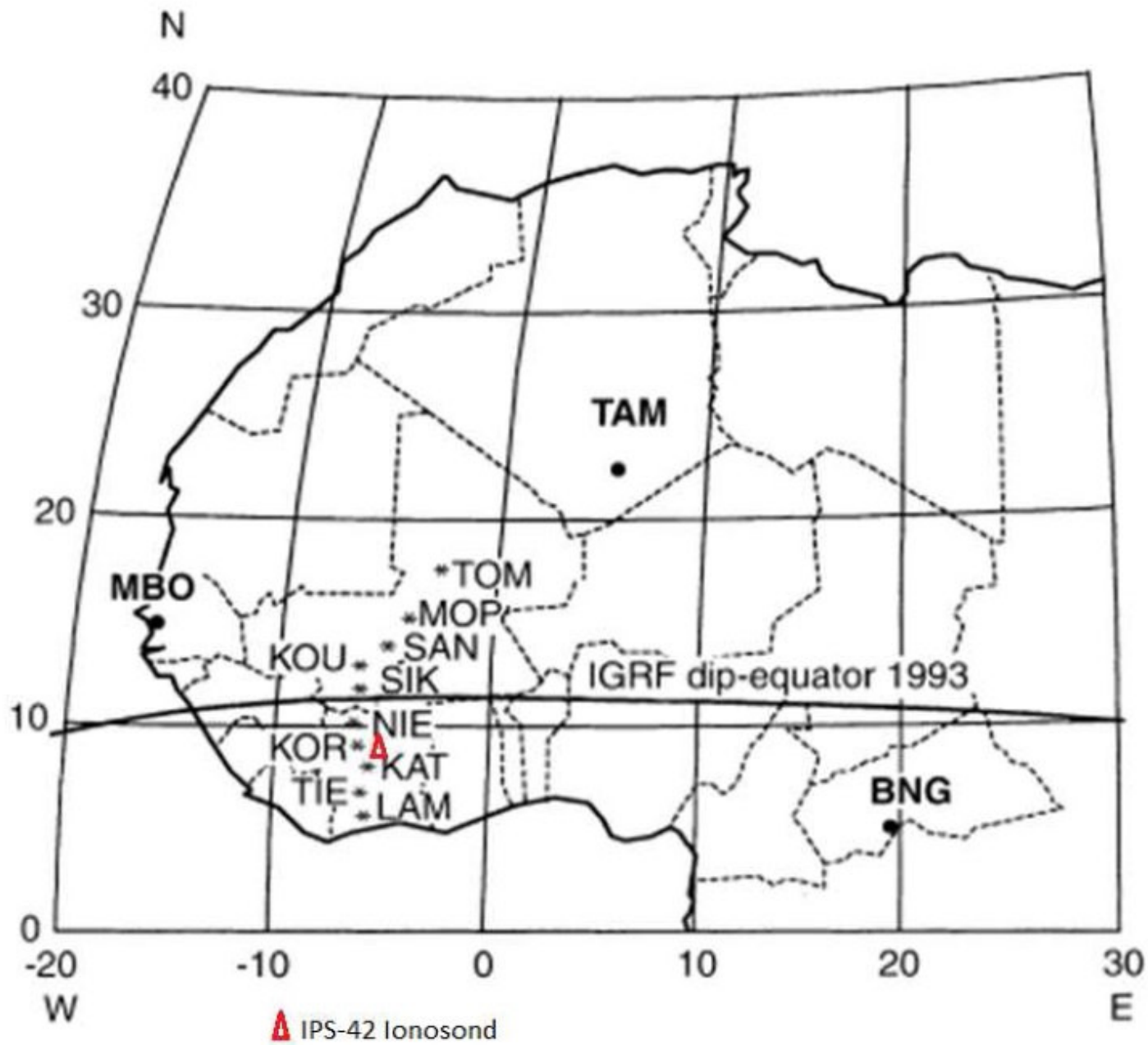

Figure 2: The $5^{\circ} \mathrm{W}$ meridian chain magnetic stations (asterisk) and the ionosonde (triangle) installed in West Africa during the International Equatorial Electrojet Year (IEEY). 

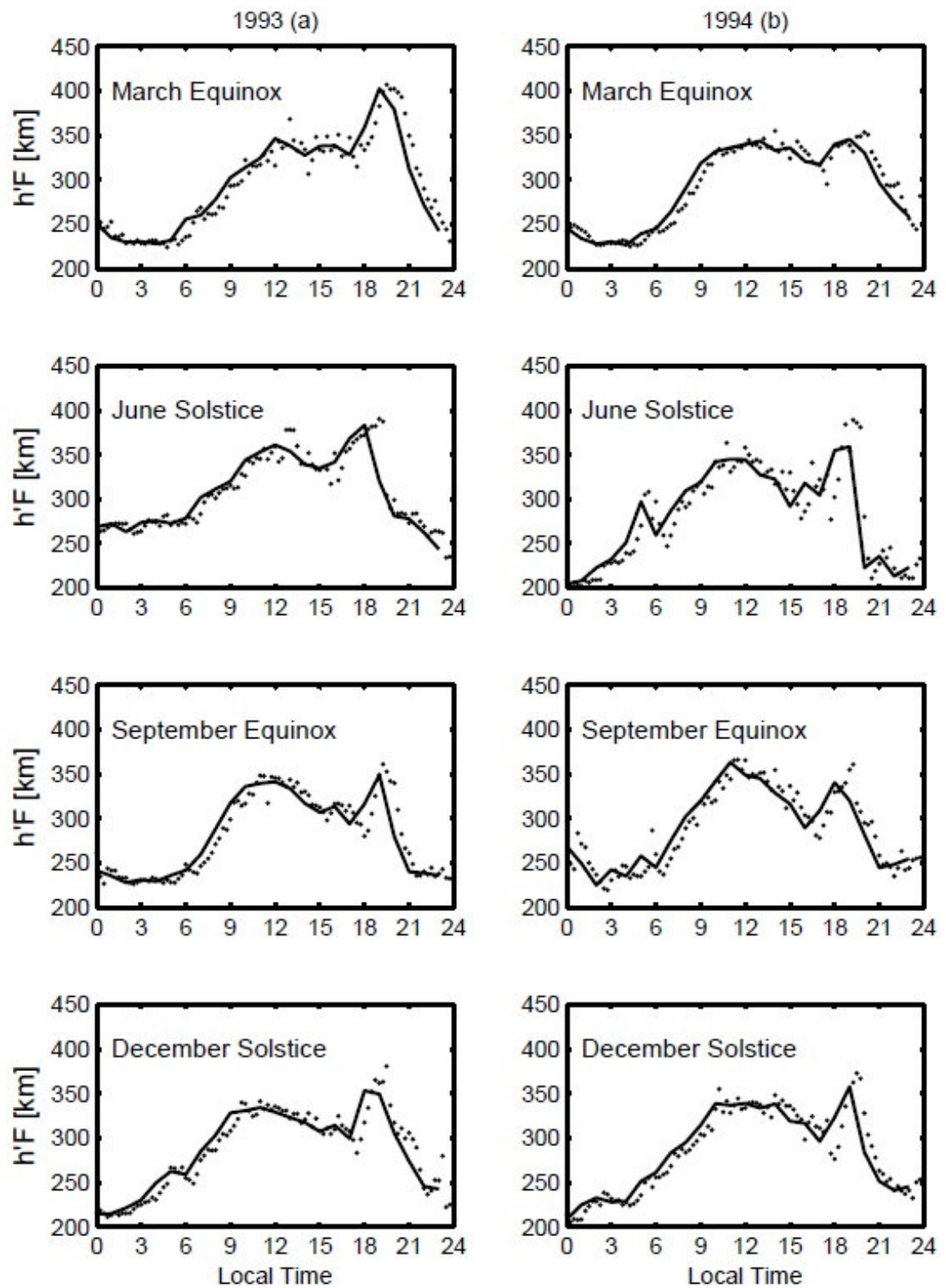

Figure 3: Daily trend of the F layer virtual heights $h^{\prime} F$ from the ISP-42 ionosonde data in 1993 (a) and 1994 (b). The dots indicate the seasonal average of the F layer virtual height at every 15 minutes and the solid lines represent the hourly averages. 


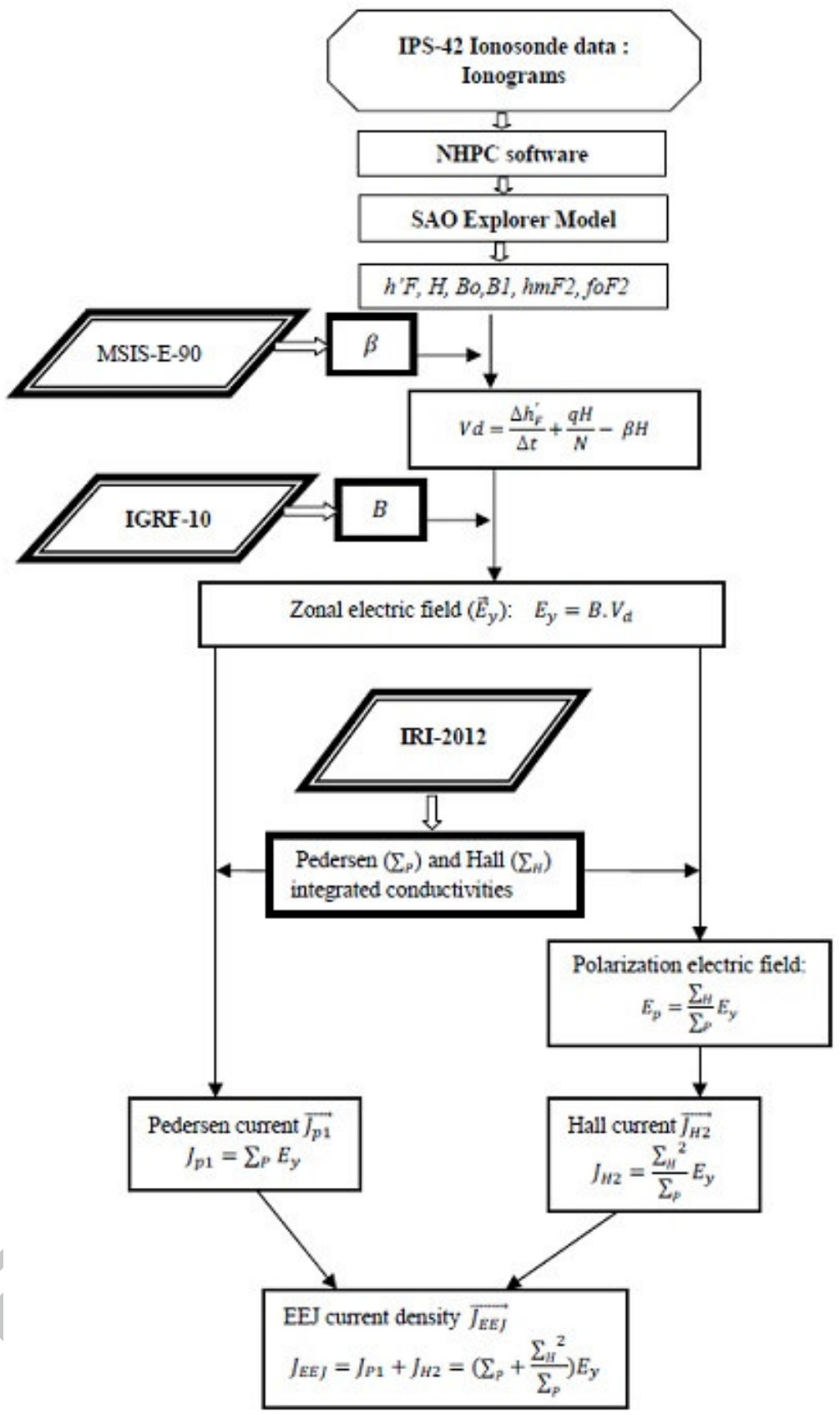

Figure 4: Diagrams of the method used to process ionosonde data for the estimation of the electric fields and current densities of the equatorial ionosphere in West Africa. 
Latitude variation of $\mathrm{H}, \mathrm{Z}$ on $24 / 02 / 93$
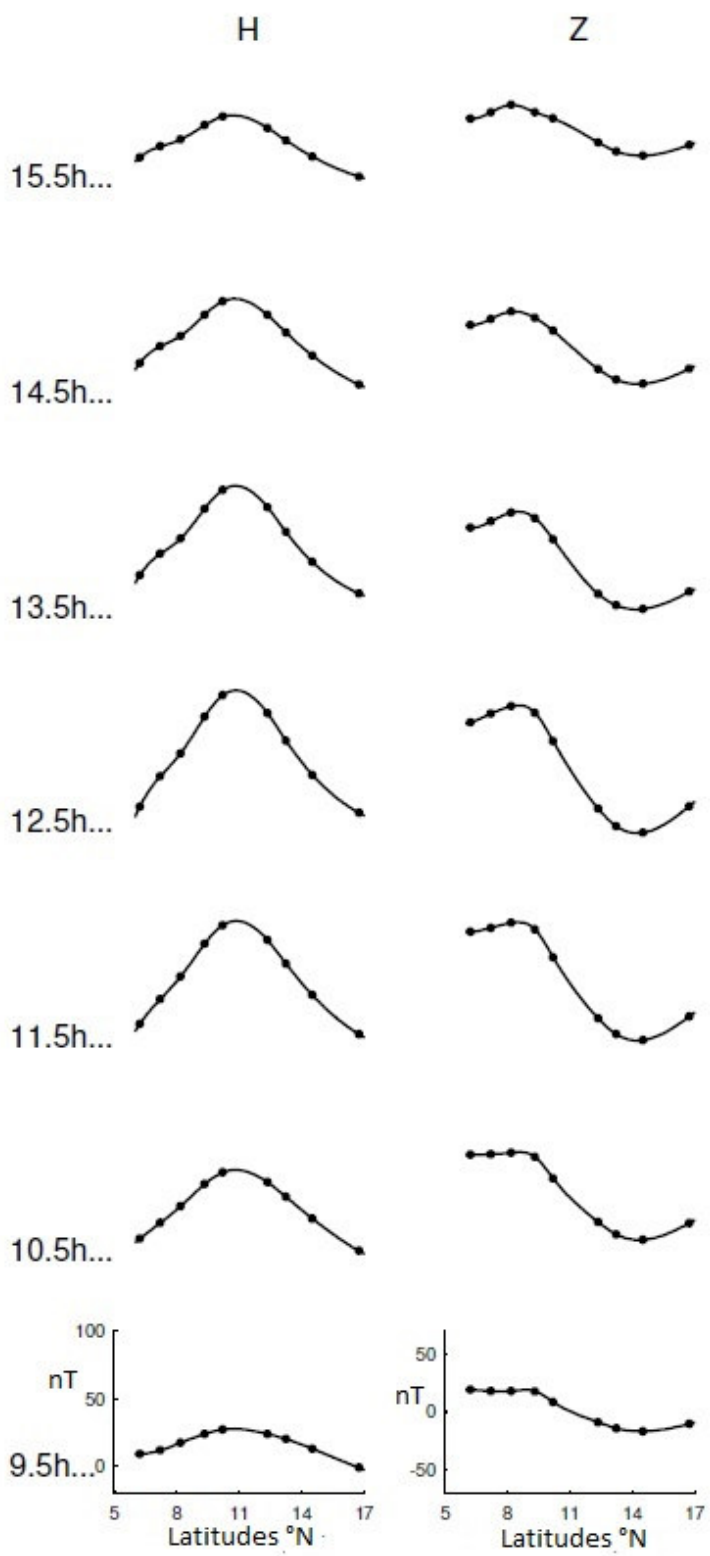

Figure 5: Latitudinal profiles of the daily regular variation $\mathrm{Sr}$ of the $\mathrm{H}$ and $\mathrm{Z}$ components of the geomagnetic field, on 24 February 1993. 

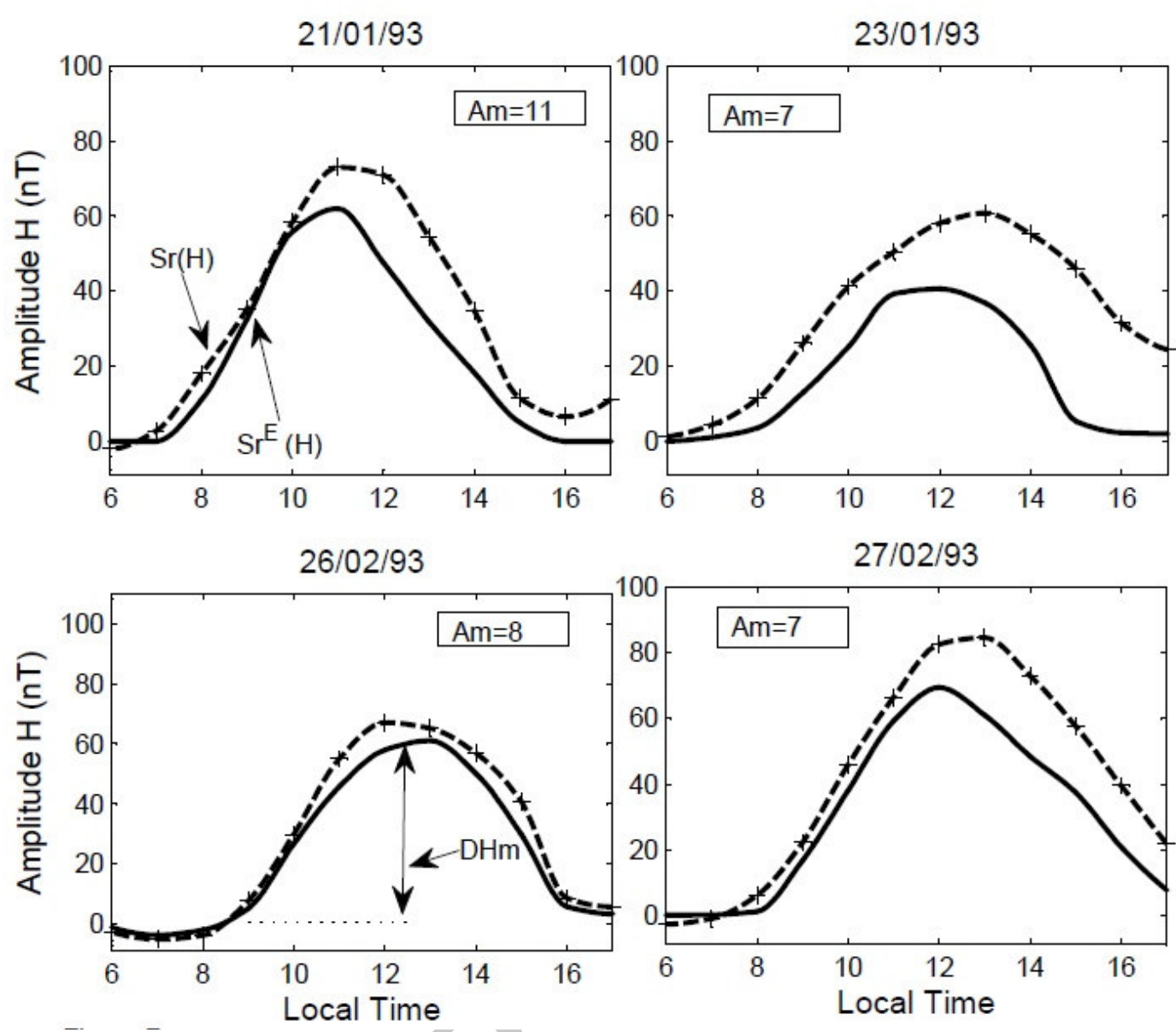

Figure 6: Daily regular variation of the horizontal component $(\mathrm{H})$ of the geomagnetic field. The dashed red lines represent the total daily regular variation $S_{r}(H)$, and the solid blue lines represent the equatorial electrojet contribution $S_{r}^{E}(H)$ in the daily regular variation $S_{r}(H)$. 
1993 (a)
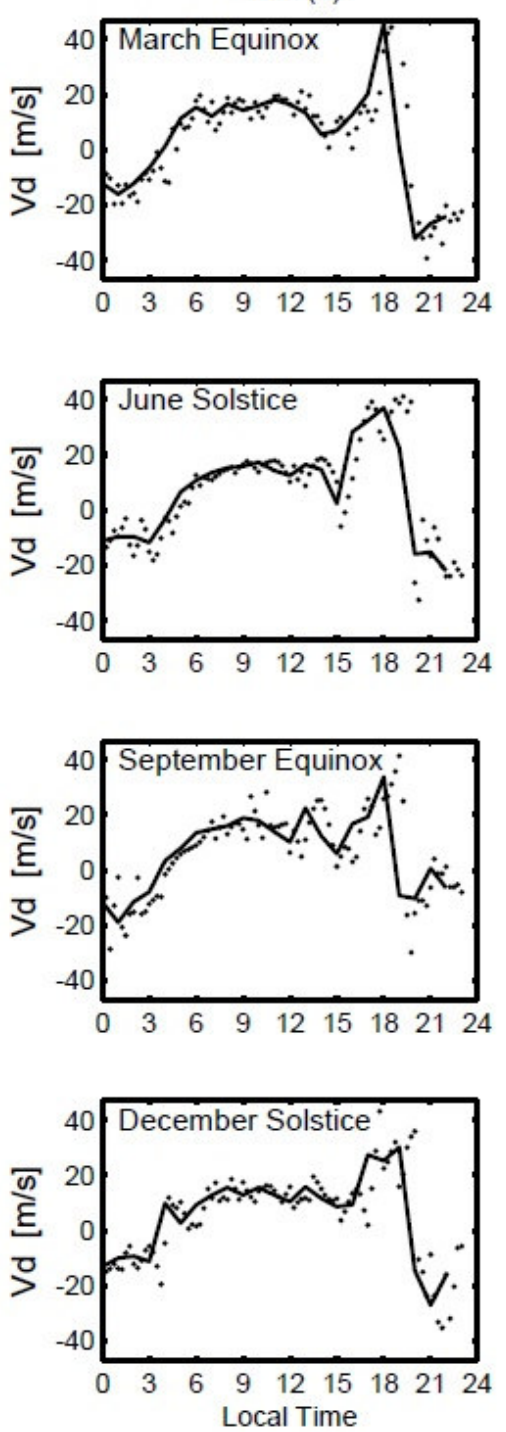

1994 (b)
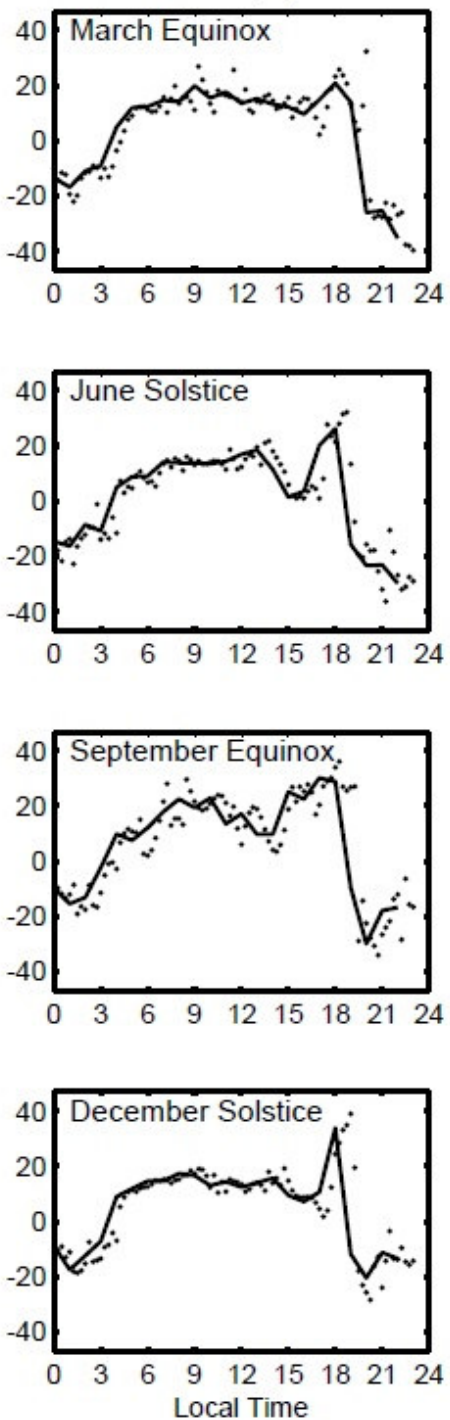

Figure 7: Daily variation of the vertical drift velocity from the ISP-42 ionosonde data in different seasons of 1993 (a) and 1994 (b). The dots indicate the seasonal averages of the vertical drift velocity at every 15 minutes and the solid lines represent the hourly averages. 

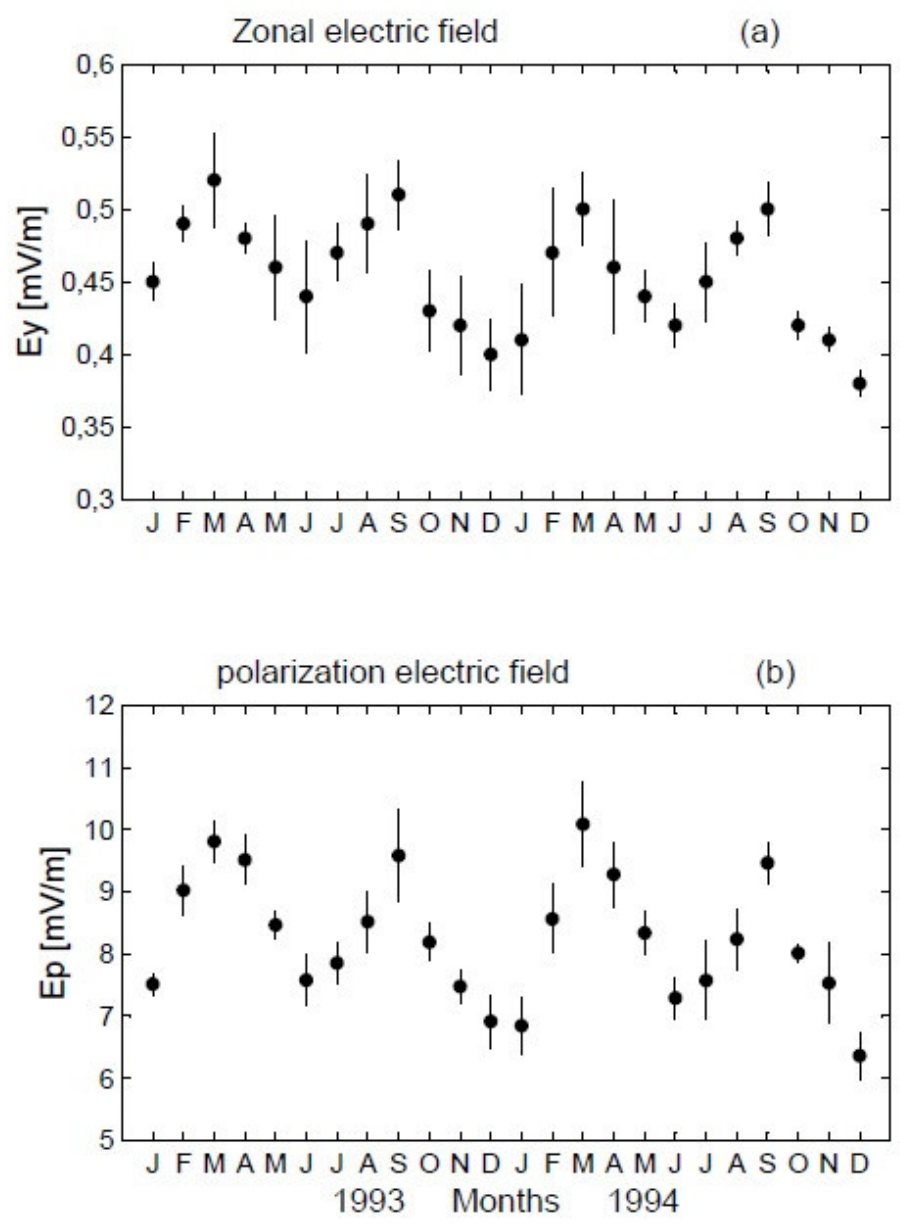

Figure 8: Seasonal variations of the Zonal electric field $E_{y}$ (a) and Polarization electric field $E_{P}$ (b). The dots represent the monthly averages of $E_{y}$ respectively $E_{P}$ from January 1993 to December 1994, the error bars indicate the standard deviations. 

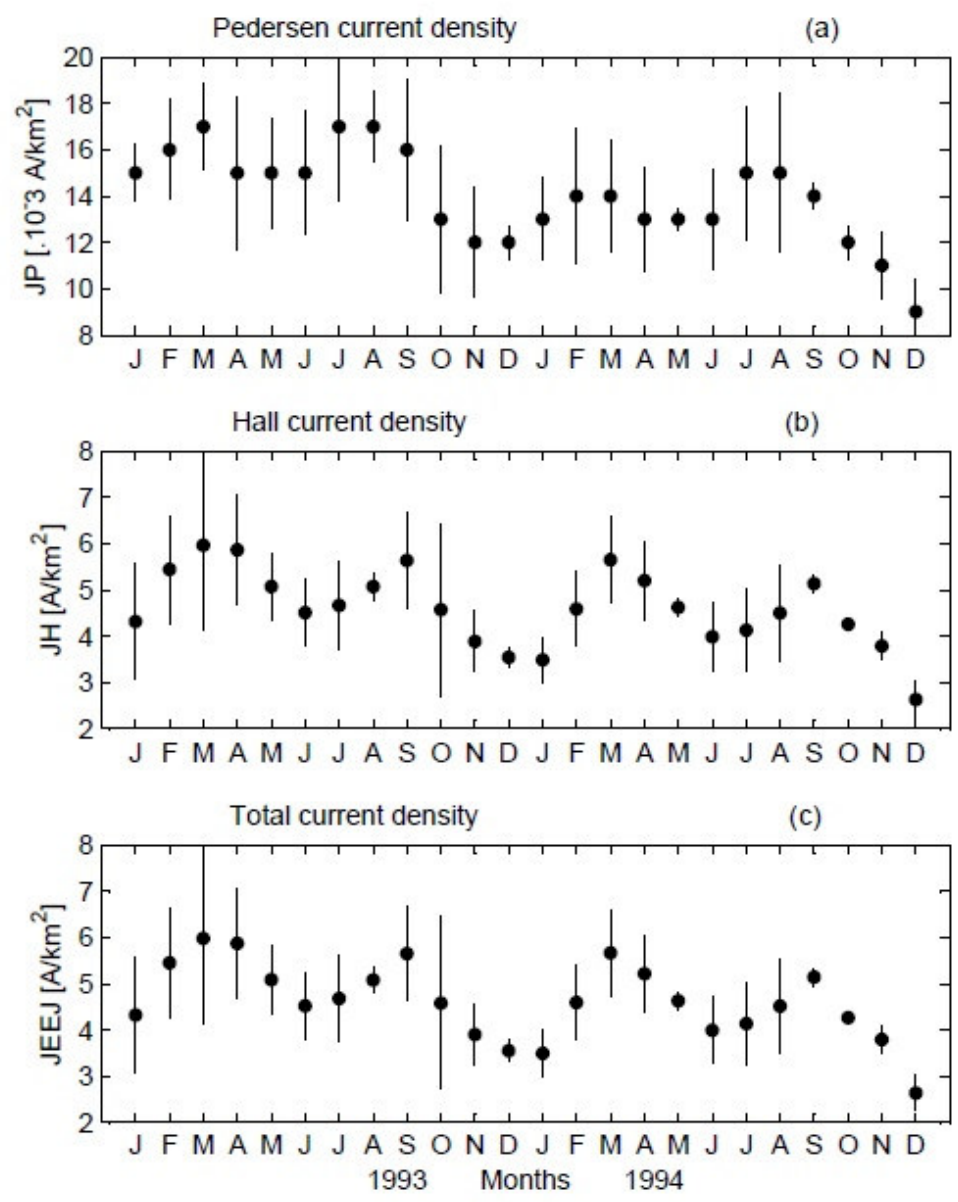

Figure 9: Variation of the eastward Pedersen (a), Hall (b) and total electrojet (c) current densities obtain from the IPS-42 ionosonde data during the two years (1993 and 1994). 


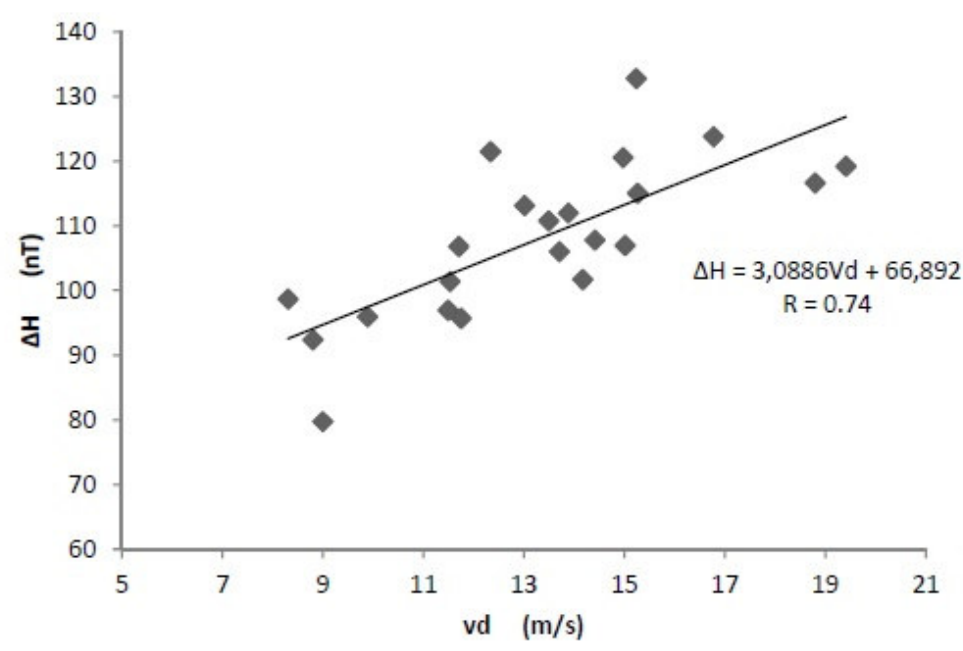

Figure 10: Correlation between the EEJ magnetic effect $\Delta H$ and the vertical drift velocity $V_{d}$ 


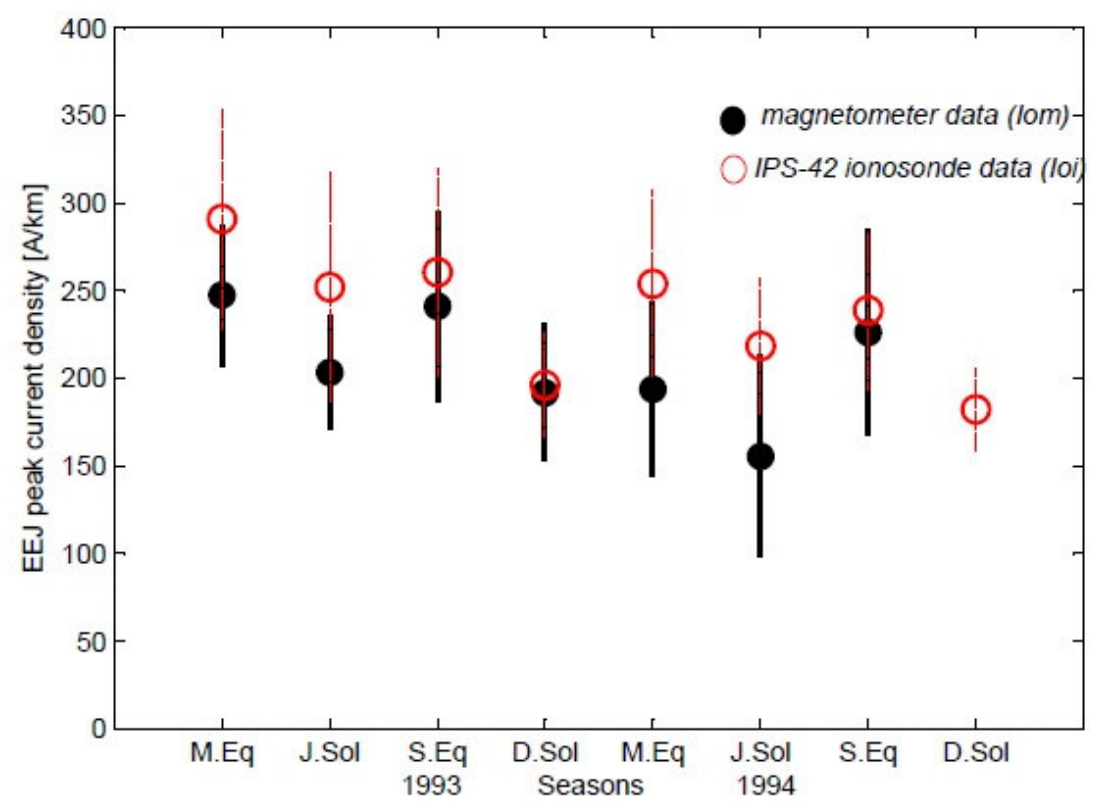

Figure 11: Comparison of the peak current density $\left(\mathrm{I}_{0}\right)$ of the equatorial electrojet obtained from the IPS-42 ionosonde data (red line) and magnetometer data (black line). 